\title{
Prospective Payments: Will DRG Compensation Reduce Medical Costs?
}

\author{
by \\ Barry Keating, Ph.D. \\ University of Notre Dame \\ and \\ Howard Addis, M.D. \\ Gerig \& Addis Surgeons, Ine.
}

\section{Introduction}

The buzzword in the health care field today is "prospective payment." Hospitals are phasing in a new system of Medicare reimbursement which covers some 26 million Americans; the system embodies the concept of the hospital knowing in advance exactly what the government will pay for a given patient (hence the term "prospective").

Hospitals which provide treatment under the fixed prospective rate may keep the change; those hospitals exceeding the prospective rate must absorb the costs themselves. Because many administrators believe such a prospective payment plan will not only cover Medicare patients (as it does now) but most hospital patients in the not-too-distant future, hospitals are beginning to use sophisticated systems to monitor individual physician resource consumption, payor activity and diagnostic trends. In short, the hospitals feel they are coming under new pressure to be cost-conscious.

Hospital behavior imposes intriguing questions for economists. It is difficult to identify their special objectives and their constraints. Since most of them are organized on a not-for-profit basis their costs tend to rise in-line with their potential revenues. Just as not-for-profit educational institutions tend to be dominated by the interests and goals of their faculty, so hospitals are run largely as physician cooperatives in which physicians rarely compare the cost of additional treatment with probable benefits.

In the recent past hospitals have been under little pressure to be efficient in any economic sense. They have not been under strong pressure from patients, because most patients are covered by third party payors. These third parties (e.g., Medicare, Blue-Cross, etc.) have usually reimbursed hospitals for costs incurred after the fact with little pressure for efficiency; the third parties have acted largely as conduits to pass on increasing costs and not as any sort of filter to screen for possible cost reductions or efficient production. Administrators and hospital trustees have been subject to much community and physician pressure to provide state-of-the-art machinery with little regard for cost considerations. Rather than minimizing costs in any competitive market sense, not-for-profit hospitals have been variously described as maximizing physician income or potential revenue. ${ }^{1}$

IAnne R. Somers, Hospital Regulation: The Dilemma of Public Policy Princeton: Industrial Relations Section, Princeton University, 1969). 
Hospital Markets

2 Hospitals actually operate in "nonmarkets" as opposed to operating in a market. The distinction between markets and nonmarkets rests with the identification of markets as situations in which prices are charged for output in competitive situations where buyers are offered the choice not only of whether to buy but from whom to purchase. Nonmarkets are conversely identified as situations in which firm output is not sold at market prices and/or at least some part of the firm's revenue is derived in the form of a subsidy (e.g., taxes, donations, block grants, etc.). While no actual situation can be perfectly described as a market or nonmarket according to these distinctions, hospitals exhibit significant nonmarket characteristics--while the product is sold at a price, the price is not determined in a predominantly competitive situation nor are the recipients of the product the ones to pay directly. In addition, a significant portion of hospital revenue has come from sources other than the sale of the product.

Not-for-profit firms operating in nonmarkets are subject to supply and demand characteristics for output quite different from that of a competitive firm. Output is difficult to define and even more difficult to measure and demand estimates are grossly unreliable because there are none of the signals we expect from competitive markets. For hospitals, the internal operating procedures are not derived in response to market pressures; in fact, even any need for internal standards is diminished because there is much less pressure to control costs than there would be in a competitive market. Hospitals may manufacture and implement internal standards which are little related or connected to the stated purpose of the hospital.

The internal standards in hospitals may be thought of as "internalities," a type of analog to the common term externality. Externalities cause divergence between individually optimal outcomes and communally optimal outcomes, while internalities may be viewed as causing a divergence between communally optimal (that is, competitive) outcomes and manager-optimal outcomes. 2 We would expect internalities which respond to the environmental stimulus of government programs--these internalities may either boost or cut costs and result in either higher or lower levels of real output than the competitive outcome (i.e., the communal optimum).

This paper examines the environmental stimulus of prospective payment plans for hospitals as implemented with DRG (diagnosis related group) based payments. More precisely, the subject of the study is to predict the organizational reactions of the individual hospitals to the new Medicare prospective payment provisions.

Government in Health Care

The initial government attempt to expand the availability of health care throughout the nation was the Hospital Survey and Construction Act of 1946 (commonly referred to as Hill-Burton).

The Act required states to adopt hospital licensing standards, which were prerequisite to receiving construction funds made available by the federal

${ }^{2}$ Charles Woolf, "A Theory of Nonmarket Failure," The Journal of Law and Economics, V. XXII (2), pp. 107-139. 
government. In addition, hospitals were required to provide a "reasonable" amount of their volume to persons unable to pay.

The rapid increase in hospital utilization which followed was viewed as leaving gaps in equal access to health care, particularly among the unemployed, poor, and elderly. As a result, the 1965 Social Security Amendments (Public law 89-97) established the Medicare program to pay for the health care costs of its beneficiaries. Part A provided reimbursement for hospital inpatient services and Part B supplemented the costs of physician services. Since 1965, the federal governments cost for Medicare Part A has increased from \$1.1 billion to $\$ 32.9$ billion in 1982 .

On September 3, 1982 President Reagan signed into law the Tax Equity and Fiscal Responsibility Act (TEFRA: P.L. 92-603). It is the most extensive 2health care spending-reduction measure so far. Medicare presently accounts for about $40 \%$ of all hospital revenues and provides hospital insurance to 26 million people ages 65 and over and 3 million disabled people. Of the $\$ 93$ billion in reductions in the act, \$14 billion is an anticipated decrease in Medicare expenditures over the next three years. Nine billion dollars of that amount is designed to come through Part A reimbursement reductions to hospitals.

Previously, Medicare paid hospitals on a cost incurred basis with little regard to the resource consumption of the patient. As a result, there has been little incentive for hospitals to limit resource utilization. With TEFRA, hospitals are not reimbursed based upon actual inpatient daily costs. Instead, the government will pay no more than a specific amount for the care of any given Medicare patient. Hospitals will receive a specified amount, regardless of the actual daily cost of care required by the patient or how long the patient requires hospitalization. In a nutshell, the act changes the payment formula from a per-day to a per-admission factor and payment is determined by a dollar rate. Each hospital will have its own dollar rate, based upon actual previous costs and adjusted (in a minor way) by an estimated inflation factor. A payment made to a hospital for a specific patient will be a function of two factors:

\section{PAYIMENT = DRG WEIGHT X DOLIAR RATE}

The government (in the form of the Health Care Financing Administration) has assigned a DRG weight to each DRG which is designed to reflect the relative costs within a specific DRG category (the DRG weight is then a relative measure of resource consumption due to a DRG classification). The actual weights range from .1842 for false labor to 6.8631 for extensive burns. The weights apply to all hospitals.

This DRG weight is multiplied by the dollar rate for the individual hospital to determine the actual payment. The dollar rate will be determined by a combination of a federally established rate and a rate which reflects the individual hospital's own cost experiences:

\section{DOLIAR RATE = FEDERAL RATE + HOSPITAL SACRIFICE RATE (Temporary)}

The "hospital specific rate" portion of the dollar rate will be phased out over a three-year period beginning in October of 1983. Beginning the fourth year (October, 1986), the federal rate will be the dollar rate (i.e., all hospitals will use the same dollar rate). 
The DRG itself is determined by the physician when he/she sets the principal diagnosis. It is the principal diagnosis stated by the physician (together with other determining factors such as age, sex, etc.) which determines the relevant DRG weight. A weight has been assigned to each of the 470 DRG numbers. It is expected that tests and procedures correspond to the listing of a specific DRG. The dollar rate is combined with an incentive system. If the hospital can care for the patient at less than this dollar rate, it is reimbursed its cost and receives a bonus. If the hospital exceeds 2this target rate, however, it will only receive a part of this excess, plus the dollar rate. In other words, hospitals which operate below the dollar rate will receive a bonus; those that do not will not be fully reimbursed.

This article examines the environmental stimulus of prospective payment plans for hospitals as implemented with DRG (diagnosis related group) based payments. Optimistically the intended result of the change to DRG is to provide hospitals with an incentive to minimize costs and compensate them for providing service to a particular group of patients. More precisely, the study analyzes, based on a sample of 34,955 patients in two hospitals, consequences for the potential reactions of hospitals to Medicare prospective payment provisions.

\section{How DRG's Work}

All payment under the prospective payment plan ultimately rests on the physician's choice of DRG for principal diagnosis. The DRG system was developed at Yale University in the 1970's as a means of reviewing use of resources; it has subsequently been refined as an inclusive method of classifying patients.

Every DRG is derived from the medical standard for disease classification which is called the International Classification of Diseases, Ninth Revision, Clinical Modification or ICD-9's. There are almost 12,000 ICD-9 classifications. Each one of these classifications was assigned to (funneled into) one of 23 Major Diagnostic Categories (see Figure 1). The $23 \mathrm{MDC}^{\prime} \mathrm{s}$ were then broken into (or pyramided into) 470 distinct groupings called Diagnosis Related Groupings each of which is said to be "medically meaningful." It is hypothesized that each DRG "can be expected to evoke a set of clinical responses which will, on a statistical average, result in approximately equal use of hospital resources." 3

From Figure 1 it is seen that the $\mathrm{DRG}^{\prime} \mathrm{s}$ are assigned from $\mathrm{MDC}^{\prime} \mathrm{s}$ on the basis of the following factors:

1) age

2) sex

3) principal diagnosis and up to four comorbidities or complications 4

4) principal procedure (if any)

5) discharge status

3American Medical Association, Diagnosis Related Groups, pamphlet, February 1984, p. 6 .

${ }^{4}$ Comorbidities are pre-existing conditions while complications are conditions that arise during a hospital stay. 


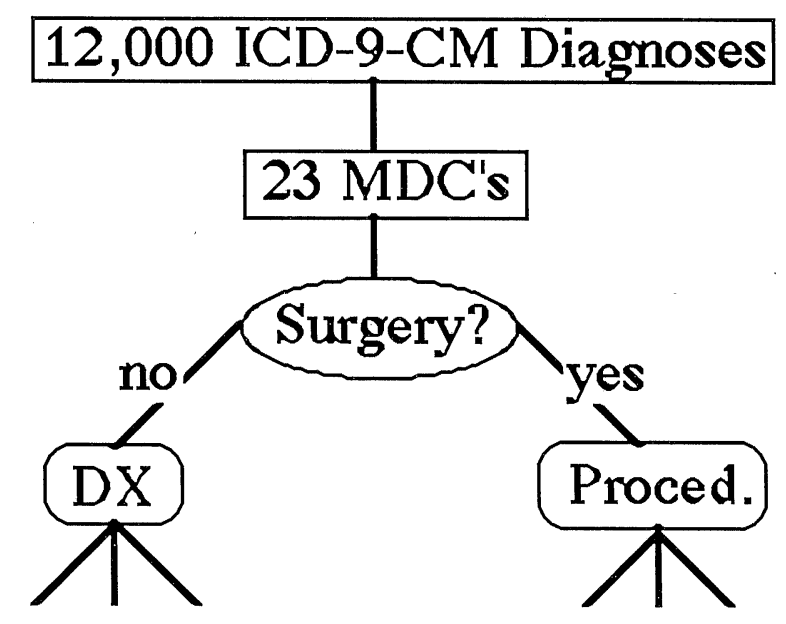

TABLE 1

IMPACT OF DRGS ON REIMBURSEMENT*

\begin{tabular}{|c|c|c|c|}
\hline DRG\# & DIAGNOSIS & DRG RATE & $\%$ DIFFERENCE \\
\hline 173 & Carcinoma of Colon & $\$ 1,370$ & \\
\hline 149 & Carcinoma of Colon With Resection & 4,827 & 72 \\
\hline 243 & - Herniated Lumbar Disc & 2,089 & \\
\hline 215 & Herniated Disc With Laminectomy & 4,748 & 56 \\
\hline 391 & Newborn With Neonatal Jaundice & 691 & \\
\hline 389 & Newborn With ABO Incompatability Jaundice & 1,175 & 42 \\
\hline 32 & Concussion & 1,058 & \\
\hline 25 & Post Concussion Syndrome & 1,550 & 32 \\
\hline 438 & Alcoholism With Cirrhosis & 1,920 & \\
\hline 202 & Cirrhosis With Alcoholism & 2,692 & 29 \\
\hline 134 & Hypertension With CHF & 2,187 & \\
\hline 127 & CHF With Hypertension & 2,996 & 27 \\
\hline $\begin{array}{l}297 \\
182\end{array}$ & $\begin{array}{l}\text { Dehydration With Gastroenteritis } \\
\text { Gastroenteritis With Dehydration }\end{array}$ & $\begin{array}{l}1,500 \\
1,969\end{array}$ & 24 \\
\hline
\end{tabular}


Clearly the most important item is the physician's principal diagnosis. Note, however, that this choice of principal versus secondary diagnosis is not without some physician discretion. Table 1 shows the percentage impact upon hospital reimbursement when the physician "flips" the principal and secondary diagnosis. Each of the seven cases displayed represents a "gray" area in medical practice in which there is some evidence for each of the DRG's to be treated as the principal diagnosis.

Under the DRG system, hospitals will be reimbursed for outliers based upon excessive treatment costs (cost outlier) or prolonged length of stay (day outlier). Outlier payments cannot exceed $6 \%$ of the total Part A Medicare payments made to the hospital.

A reimbursement differential for urban and rural hospitals also exists. In the first year, there is an urban and rural DRG rate schedule for each of the nine regions. By 1987, when regional differences are eliminated, there will be two DRG payment schedules; a national rural and a national urban schedule.

DRG rates have been determined using averages based upon hospital charge data. In 1984 and 1985, the prices will be adjusted by a market basket index of hospital costs, plus 1\%. Beginning in 1986, the increase in DRG rates will be determined by the HHS secretary and reviewed by a 15-member commission appointed by the Office of Technology Assessment.

Table 2 illustrates the government's anticipated reductions in TEFRA medicare expenditures for hospitals during the next three years.

Table 3 illustrates the differences in hospital charges and reimbursements before TEFRA. The financial impact to a given hospital. depended upon its proportion of Medicare patient days to total patient days. Interestingly, in 1981 Medicare reimbursements for hospital allowable costs were only 68.7\% of the total approved Medicare charges. Contractually hospitals were prohibited by Medicare from billing patients for the remaining 31.3\%.

Description of the Sample

Data for this study were collected on 34,955 patients which represent the population for one year of two hospitals in the Midwest. The data was in the form of discharge reports which are required by the new prospective payment plan as the document from which $\mathrm{DRG}^{\prime} \mathrm{s}$ are assigned. The year examined is the fiscal year just prior to the implementation of prospective payment for Medicare patients.

DRGs were assigned to each diagnosis (there is often more than one per patient--the maximum is 5) for each patient by means of a "grouper" program. The grouper performs the algorithm outlined in Figure 1. First, a diagnosis, which is one of the 12,000 ICD-9-CM numbers is reduced to one of the 23 MDC numbers or categories. Then the program checks the patients record for surgery and selects the appropriate branch. Finally, the grouper observes the patients age, sex, complications or comorbidity and discharge status and finally selects one of the 470 DRG numbers.

A separate program optimizes the DRG selection by rearranging the order of the DRGS (recall, a patient will have up to 5 DRGs associated with them depending on the number of diagnoses the attending physician listed) in order to maximize payment to the hospital. The use of the grouper and optimizer packages is explained below. 
TABLE 3

GOVERNMENT EXPECTATIONS OF MEDICARE REDUCTIONS

$1983-1985$ (in \$ Millions)

\begin{tabular}{|c|c|c|}
\hline Year & Total & Hospital Portion \\
\hline 1983 & 2,867 & 1,987 \\
\hline 1984 & 4,423 & 2,780 \\
\hline 1985 & 5,961 & 3,939 \\
\hline
\end{tabular}

Source: Tax Equity and Fiscal Responsibility Act of 1982, P.L. 97-248, U.S. Government Printing Office, Washington, D.C., 1982.

TABLE 2

U.S. PATIENT-DAY UTILIZATON PER 1,000 POPULATION, 1970-1990

\begin{tabular}{|c|c|c|c|}
\hline Year & Under 65 & $65-74$ & 75 and Over \\
\hline 1970 & 920 & 2,760 & 7,360 \\
\hline 1975 & 910 & 2,730 & 7,280 \\
\hline 1980 & 860 & 2,580 & 6,880 \\
\hline $1985 \S$ & 850 & 2,550 & 6,800 \\
\hline $1990 \S$ & 840 & 2,520 & 6,720 \\
\hline
\end{tabular}

Source: National Hospital Discharge Survey, National Center for Health Statistics, Series 13, No. 60, p. 17.

$\S$ Projection 
Empirical Results

We should be able to answer three questions regarding the hospital response to prospective payment using DRG-based payments:

1) If the hospitals in the sample "changed nothing" and continued to operate in the first year of prospective payments as they had in the year before, what would the effect on the hospital be? Would those hospitals be reimbursed at a higher rate after DRG-based payments or would they find themselves worse off?

2) Assuming nothing changed with the installment of DRG-based payments in hospital behavior except the order of some Medicare diagnoses, would the hospitals be considerably better off? could the hospitals alter their reimbursement by making changes in the order of diagnoses (within the new Medicare rules)?

3) Are the DRG-based payments neutral with respect to payer category? If all patients were paid for under the DRG-based payments, would all patients be treated in the same manner?

Each of these questions becomes central to determining (or predicting) how hospitals will respond to the new Medicare payments mechanism.

Certainly of interest to hospitals is how they will fare financially under the prospective payment plan. In order to approach this question we assume that each of the hospitals will incur a patient mix identical to the one for the year preceding prospective payment.

We then examined each of the 8,245 Medicare patients in that year by using a grouper program on them to change their diagnoses to one of $23 \mathrm{MDC}^{\prime} \mathrm{s}$ and, in turn, to use other patient information (such as age, sex, etc.) to further classify them into one of the 470 DRG categories.

Once a set of $\mathrm{DRG}^{\prime} \mathrm{s}$ was assigned to each of the patients we used the hospitals dollar rate for the first year of prospective payments along with the DRG weights to determine the reimbursement which the hospital would have received if each patient had been hospitalized the following year.

This DRG-determined reimbursement was divided by the actual charges which the hospital levied on that patient. Table 4 shows this "percent reimbursement" figure for each of 6 different payer classes (although only Medicare has DRG-based payments in most of the country at this time). Note that for Medicare patients the mean of these percent reimbursements is 1.2868 meaning that the hospitals could expect to be reimbursed approximately 128\% of the charges which they actually levied on those patients the previous year.

DRG weights and dollar rate are designed to supposedly accurately reflect resources used. The clear inference, however, and the answer to our first question, is that the hospitals may be better off with DRG-based reimbursements for Medicare patients. In fact, examination of Table 4 suggests that DRG-based payment would mean more revenue for the hospital regardless of the patients financial affiliation.

The mean ratios in Table 4 indicate that DRG compensation with respect to previous charges is less for Medicare patients than for any other payment group. The difference suggests three possibilities. First, the increase in the return for Medicare patients under the new system is underestimated in Table 4 because, under the old system, hospitals only realized 70 percent of charges. Secondly, if one were to adjust ratios for actual compensation rather than charges and if DRGs represent true unbiased costs, then the hospitals 
previously shifted costs from Medicare patients to other groups. 5 Finally, if one assumes that charges under the old system reflected true costs, then the significantly lower ratio for Medicare patients indicates that the DRG weights are not neutral with respect to those ilinesses frequently incurred by Medicare recipients.

The answer to our second question (Could hospitals alter their reimbursement?) was examined by observing the DRG-weights for each DRG listed on a patient's discharge sheet. Since Medicare pays for only the first DRG listed, there is the possibility of switching the order in which the DRG's are listed in order to place the DRG with the highest weight at the top of the list. Often this switching is perfectly legitimate--it is legitimate in any case in which the hospital can medically justify the switch of primary diagnoses.

our approach was to switch in every case in which a higher DRG-weight would be listed as the primary diagnosis. Of course, some of these switches would be disallowed in actual practice, but the magnitude of the effect of making all the possible switches should indicate if hospitals will have any incentives to engage in the activity.

Table 5 indicates that a 7.44 percent increase in payments would be received if all possible switches were allowed. For non-Medicare patients (who are not now paid for by DRG numbers) this figure varies but is always less than 10 percent. There appears to be some financial incentive to optimize diagnoses.

The final question, dealt with in this study, namely neutrality with respect to payer category (i.e., Medicare, Commercial, Self-Pay, etc.), was already alluded to in analyzing the results of the first question. If the DRG weights are true measures of resources actually used we might expect the reimbursements to hospitals to be either slightly above or slightly below charges but it should not vary with respect to the patient's financial category. DRG's are said to". . . define the products of the hospital in terms of classes of patients utilizing similar resources." 6 The implication is that $\mathrm{DRG}^{\prime} \mathrm{s}$ should be neutral with respect to whom is paying the bill--in fact, they are not.

Table 6 displays t-tests examining the percentage reimbursement of Medicare patients and other payer categories. Since the numbers of patients involved are large and the corresponding degrees of freedom in these tests are also large, we are confident that the percentage reimbursements vary rather dramatically from one group to another. Each of the t-tests is significant at the 99\% level whether the pooled or separate variance estimates are used.

Table 4 also presents a one-way analysis of variance for these same payer categories. It too is significant at the 99\% level. In other words, the percentage reimbursement varies in a nonrandom fashion from one payer category to another. The Medicare category has the lowest mean percentage reimbursement of all payer categories.

5 See "Cost Shifting: An Empirical Examination of Hospital Bureaucracy," by Barry Keating in Applied Economics (April 1984), Volume 16, No. 2, pp. 279289.

${ }^{6}$ Letter from Robert B. Fetter of the Yale School of Organization and Management to AMA members. Dr. Fetter was the principal investigator on the project creating the current DRG system. 


\section{TABLE 4}

ONE-WAY ANALYSIS OF VARIANCE

(Percent Reimbursement by Payer Financial Class)

\begin{tabular}{|c|c|c|c|c|c|c|c|}
\hline & of $\stackrel{\#}{\text { Cases }}$ & Mean & $\begin{array}{l}\text { Std. } \\
\text { Dev. }\end{array}$ & Minimum & Maximum & F-Ratio & $\begin{array}{l}\text { F. Prob- } \\
\text { ability }\end{array}$ \\
\hline Medicare & 8,285 & 1.2864 & 1.2422 & 0.0294 & 28.3312 & & \\
\hline Medicaid & 1,419 & 1.4703 & 1.2756 & 0.0812 & 13.4677 & & \\
\hline Biue-Cross & 6,010 & 1.3847 & 1.4299 & 0.0417 & 32.3101 & & \\
\hline Commercial & 11,771 & 1.4326 & 1.3855 & 0.0218 & 45.7336 & 22.029 & 0.0000 \\
\hline Self-Pay & 3,885 & 1.5261 & 1.5903 & 0.0143 & 29.3301 & & \\
\hline $\begin{array}{l}\text { Workman's } \\
\text { Comp }\end{array}$ & 191 & 1.7240 & 1.1680 & 0.0599 & 8.5838 & & \\
\hline TOTAL & 31,561 & 1.4001 & 1.3818 & 0.0143 & 45.7336 & & \\
\hline
\end{tabular}

TABLE 5

PERCENTAGE INCREASES IN REIMBURSEMENT

BROUGHT ABOUT BY DRG-SWITCHING

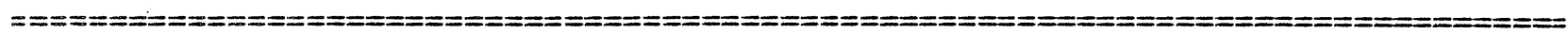

Financial Class of Patient

Percentage Increase in Reimbursement

Medicare

7.44

Medicaid

9.26

Commercial

6.63

Self-Pay

5.91

Workman's Comp

6.99 
OL

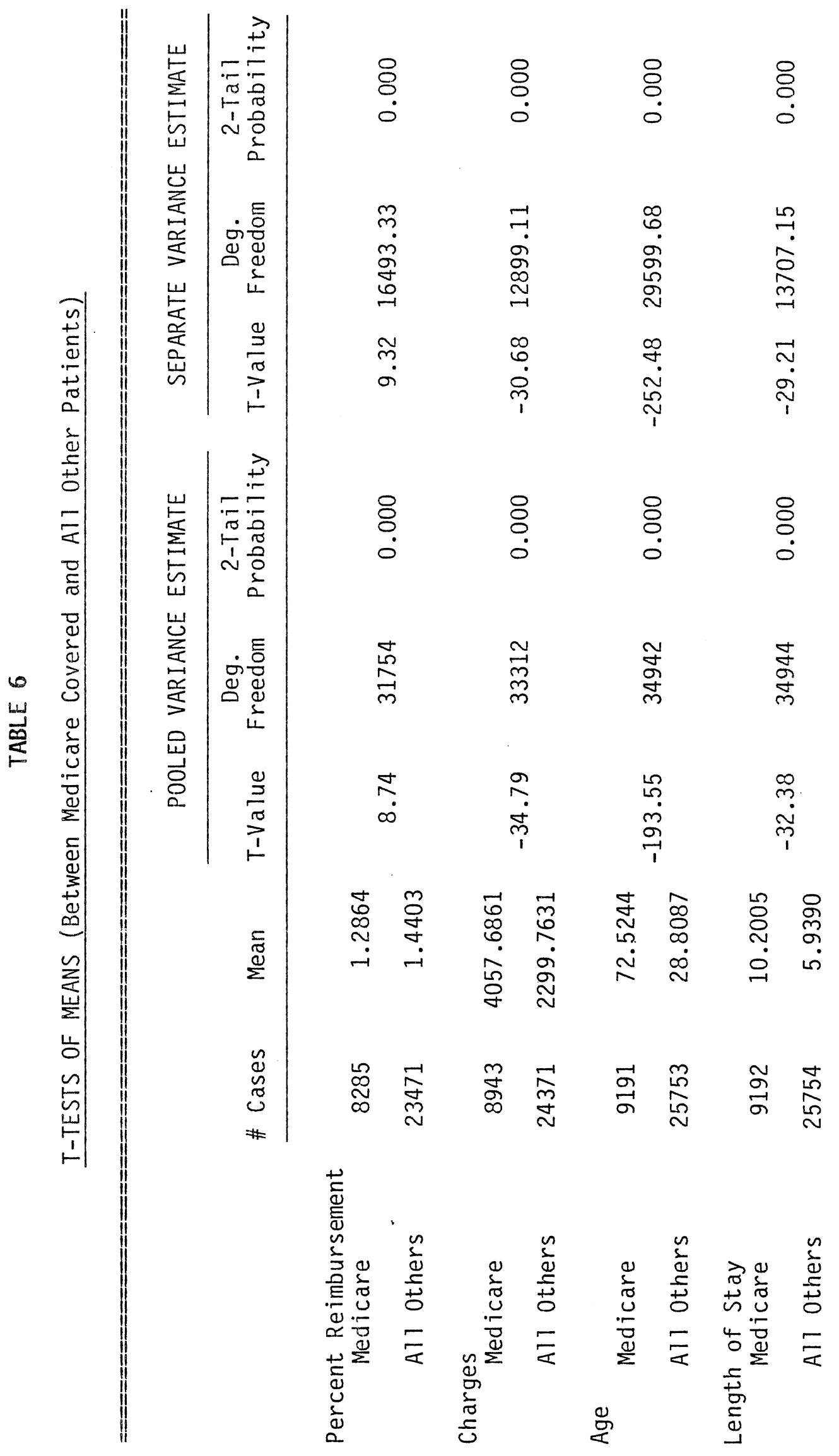


But how could this be? It would be expected that all payer categories (if resource use was accurately measured) would present about the same percentage reimbursement with only random variation from group to group. Present here, however, is a systematic variation in DRG weights when examined by payer class.

Whether this is a conscious effort to manipulate intensities of treatment by payer category or simply a demonstration that the DRG system does not actually measure true resource costs is unclear. What is clear from Table 5 is that we can likely expect higher reimbursements in the early stages of DRG implementation and that any reduction in expenditures will likely take place through adjustments to the base rate (i.e., dollar rate) set by the Health Care Financing Administration) .

\section{References}

American Medical Association, Diagnosis Related Groups, pamphlet, February $1984, \mathrm{p} .6$.

Horn, Susan D., "The Role of Severity-Adjusted Case Mix in Hospital Management," unpublished working paper, Johns Hopkins University Center for Hospital Finance and Management.

Keating, Barry, "Cost Shifting: An Empirical Examination of Hospital Bureaucracy," Applied Economies, V. 16, No. 2, pp. 279-289.

Lindsay, Cotton M. and Williams, Robert, "The Effectiveness of Government Health Policy," unpublished working paper, UCLA Department of Economics. 